\title{
Synovial fluid lactate levels in septic and non-septic arthritides
}

\author{
C. GOBELET AND J. C. GERSTER
}

From the Department of Rheumatology and Physical Medicine, Centre Hospitalier Universitaire Vaudois (CHUV), Lausanne, Switzerland

SUMMARY Lactate concentration was studied in 383 synovial fluid specimens from patients with various arthritides. The highest concentrations of lactate occurred in non-gonococcal septic synovial fluids. High values were recorded in seropositive rheumatoid arthritis and crystalinduced arthritides, medium values in synovial fluids from seronegative rheumatoid arthritis, seronegative spondylarthritides, gonococcal arthritis and haemarthrosis, and the lowest values in aspirates from osteoarthrotic joints. There was a positive correlation between synovial $\mathrm{pH}$ and lactic acid concentration. These data suggest that determination of lactate in synovial fluid can be valuable in the rapid exclusion of septic arthritis. Its value for differentiating between other inflammatory arthritides is discussed.

Synovitis, the basis of inflammatory joint disease, can be of different histological types. The metabolism of the synovium is determined by many factors, including histological changes (hyperplasia of the synovial lining cell layer, infiltration of inflammatory cells), intra-articular pressure, and obliterative microangiopathy. ${ }^{1-7}$ Synovial glucose metabolism via the anaerobic pathway producing lactate excess occurs in certain conditions, particularly infection. A rapid diagnostic test for septic arthritis is needed since delay in therapy can lead to irreversible joint damage. ${ }^{8}$ Estimation of synovial fluid (SF) lactic acid has been advocated as a rapid screening test. ${ }^{9-15}$ Results of lactate concentration in septic conditions are compared in this study with those obtained in different inflammatory and non-inflammatory rheumatic conditions.

\section{Materials and methods}

Three hundred and eighty-three in- and outpatients attending our Rheumatology Centre had an SF lactate estimation between January 1977 and December 1982. Based on clinical, radiological, and biological data, a subdivision of the patients into eight groups was carried out (Table 1): seropositive rheumatoid arthritis (RA), seronegative RA, seronegative spondylarthritis (SNS), crystal-induced arthritis, non-gonococcal infective arthritis of diffe-

Accepted for publication 1 January 1984.

Correspondence to C. Gobelet, Department of Rheumatology and Physical Medicine, CHUV 1011 Lausanne, Switzerland. rent aetiologies, gonococcal arthritis, post-traumatic haemarthrosis, and osteoarthrosis. Among 51 cases of SNS were 36 patients with Reiter's syndrome, 8 with psoriatic arthritis, and 7 with ankylosing spondylitis. The 100 cases of crystal-induced arthropathies (all with acute synovitis) comprised 56 patients with gout and 44 with CPPD crystal deposition disease. The bacteria cultured from SF specimens from patients with non-gonococcal septic arthritides are listed in Table 1 , the most common

\section{Table 1 Data on 383 cases}

\begin{tabular}{lr} 
1. Seropositive rheumatoid arthritis & 61 \\
2. Seronegative rheumatoid arthritis & 32 \\
3. Crystal-induced arthritides & 100 \\
4. Seronegative spondylarthritides & 51 \\
5. Osteoarthrosis & 76 \\
6. Post-traumatic haemarthrosis & 20 \\
7. Non-gonococcal infectious arthritides & \\
$\quad$ Gram-positive cocci & \\
$\quad$ Staphylococcus aureus & 16 \\
$\quad$ Streptococcus & 4 \\
$\quad$ Gram-negative bacilli & \\
$\quad$ Pseudomonas aeruginosa & 2 \\
$\quad$ Proteus mirabilis & 1 \\
$\quad$ E. coli & 2 \\
$\quad$ Serratia marcescens & 1 \\
$\quad$ Others & \\
$\quad$ Candida albicans & 1 \\
$\quad$ Mycobacterium tuberculosis & 1 \\
8. Gonococcal arthritis & 15 \\
$\quad$ Neisseria gonorrheae & 383 \\
Total number & \\
\hline
\end{tabular}




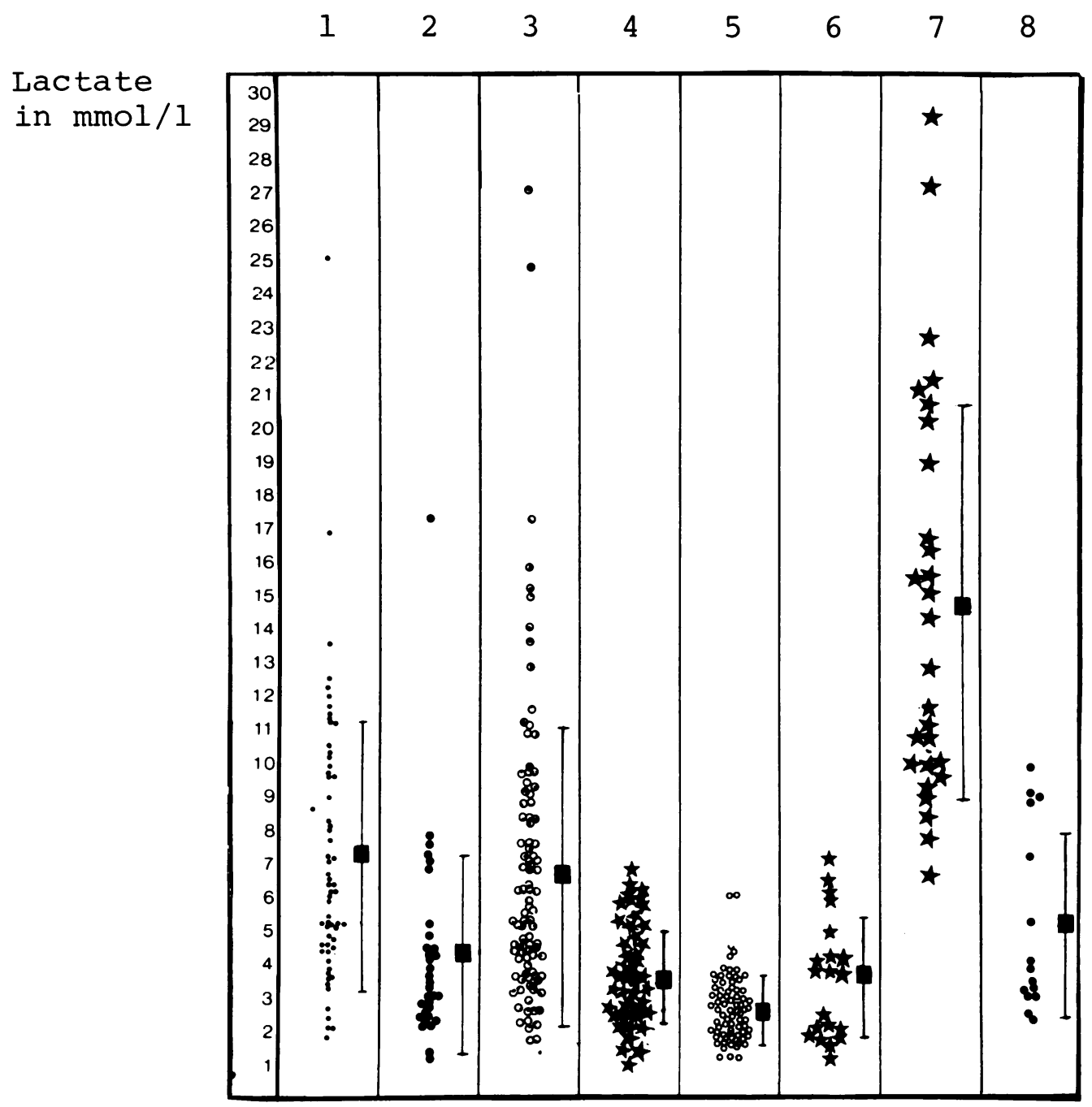

Fig. 1 Synovial fluid lactate mean values for different synovial effusions ( $n=383)$ in mmolll. Mean values $\pm S D$ and range. (1) Seropositive rheumatoid arthritis, $n=61$. (2) Seronegative rheumatoid arthritis, $n=32$. (3) Microcrystal-induced arthropathies, $n=100$. (4) Seronegative spondylarthritides, $n=51$. (5) Osteoarthrosis, $n=76$ ). (6) Haemarthrosis, $n=20$. (7) Septic arthritides other than gonococcal, $n=28$. (8) Gonococcal arthritis, $n=15$.

organisms being Staphylococcus aureus (16 cases). Infection with Neisseria gonorrheae (15 cases) was diagnosed on the basis of positive SF cultures and/or isolation of the organism from the genitalia and full response of penicillin therapy. All cultures and SF lactate determination were performed before antibiotic therapy was started.

Synovial fluids were collected aseptically in plastic tubes and centrifuged without anticoagulant.
Lactate analysis was performed on the supernatant within 2 hours by standard laboratory LDH procedure and Roche 640 automatic analyser, ${ }^{16}$ a sample of only $0.5 \mathrm{ml}$ of SF being required. Results in $\mathrm{mmol} / \mathrm{l}$ were available in about one minute. In 18 specimens synovial $\mathrm{pH}$ was estimated simultaneously by a gazometer $\mathrm{ABL}_{3}$ (Radiometer, Copenhagen). Statistical analysis of results was by Student's $t$ test. 
Table 2 Synovial fluid lactate mean values $( \pm S D)$ related to the infecting organism ( $n=$ number of patients)

\begin{tabular}{llcc}
\hline & Gram + & Gram- & Gonococcus \\
\hline $\mathrm{n}$ & 20 & 6 & 15 \\
Mean values & 15.8 & 13.6 & $5 \cdot 3$ \\
\pm SD & 5.9 & 4.8 & 2.6 \\
\hline & \multirow{N}{*}{$\leftarrow$} & $\underset{\mathrm{p}<0.001}{\longrightarrow}$
\end{tabular}

\section{Results}

Average synovial fluid lactic acid level in the eight groups. Synovial lactate concentrations are presented in Fig. 1. The results fell into four categories. In non-gonococcal septic arthritides the mean level was $15 \cdot 1 \pm 5 \cdot 7 \mathrm{nmol} / \mathrm{l}( \pm \mathrm{SD})$. This value was significantly higher than that in all other groups. Seropositive RA and crystal-induced arthritides were grouped together with mean values of $7 \cdot 2 \pm 4 \cdot 0$ and $6 \cdot 65 \pm 4 \cdot 4$ respectively, and in osteoarthrosis the average concentration was $2 \cdot 6 \pm 0 \cdot 9$, which was significantly lower than all other rheumatic diseases.

Seronegative RA, SNS, gonococcal arthritis, and haemarthrosis gave similar lactate levels of $4 \cdot 2 \pm 2 \cdot 9$, $3 \cdot 5 \pm 1 \cdot 3,5 \cdot 3 \pm 2 \cdot 6$, and $3 \cdot 61 \pm 1 \cdot 8$ respectively. There was no statistically significant difference between the results of these four diagnostic categories, though they differed significantly from the other groups.

As can be seen in Fig. 1, lactate values were grouped closely together in seronegative RA, SNS, osteoarthrosis, and haemarthrosis but were widely scattered in seropositive RA, crystal-induced and septic arthritides, with overlap in these groups. In septic arthritides the average lactate level did not significantly differ between those due to Grampositive and Gram-negative organisms, but was significantly lower in the SF of gonococcal arthritis (Table 2).

Relationship of lactate concentration to $\mathrm{pH}$. A fall in $\mathrm{SF}$ pH level correlated with a rise in lactic acid concentration $(r=-0.88 ; y=7 \cdot 534+(-0 \cdot 547 x))$.

\section{Discussion}

Attention has been drawn to the usefulness of SF lactate determination for rapid diagnosis of infection. ${ }^{9-15}$ The aim of this study was to compare lactate values in septic and non-septic arthritides. Three hundred and eighty-three specimens from 383 patients were assessed.

Very high concentrations of lactate were detected in non-gonococcal septic arthritides. Contrary to the findings of Brook et al. ${ }^{9}$ average values from Gram-positive cocci and Gram-negative bacilli were not found to be significantly different. A value as high as $18 \mathrm{mmol} / \mathrm{l}$ was recorded in a case of Candida albicans arthritis. Values lower than $9.4 \mathrm{mmol} / \mathrm{l}$ were found in $14.3 \%$ of infected fluids, including one case of tuberculous infection. Average values recorded in gonococcal arthritis were significantly lower, one value only being greater than $9.4 \mathrm{mmol} / \mathrm{l}$. These results are in agreement with most of the previous studies, ${ }^{910}$ whether the method of determining lactate was gas liquid chromatography or enzymatic reaction, the latter being the method used in this study.

High values of lactate were found in seropositive RA and crystal-induced arthritides. In about $29.5 \%$ of the seropositive RA and $19 \%$ of the crystalinduced arthritides without superimposed infection the results were above $9.4 \mathrm{mmol} / \mathrm{l}$. In view of the overlap with the results of septic effusions some caution should be observed in the interpretation of the results, and priority should be given to SF cultures and clinical presentation.

It can be assumed that high concentration of lactate is the result of increased glucose utilisation and conversion to lactic acid under anaerobic conditions in the inflamed synovium. Hypoxia could be favoured by synovial necrosis and obliterative microangiography. There is also evidence that the presence of bacteria exerts an additional influence. As already reported, ${ }^{7}$ vascular imbalance could induce synovial oedema and anaerobic glucose consumption. Whether intra-articular pressure could play a role in hypoxia remains debatable but is probable in view of the findings of Jayson et al. ${ }^{5}$ and Richman et al. ${ }^{6}$

The increased transformation of the glucose metabolism to an anaerobic pathway in SF is strongly suggested by the data of Treuhaft and McCarty. ${ }^{17} \mathrm{~A}$ fall in $\mathrm{SF} \mathrm{Po}_{2}$ and $\mathrm{pH}$ level correlates with a rise in lactic acid. In addition it has been shown in a previous study ${ }^{13}$ that there was a significant positive correlation between SF lactate and lacticodehydrogenase levels, whereas leucocyte counts in the SF did not correlate with the lactic acid level. As suggested by Arthur et al. ${ }^{14}$ leucocyte breakdown products should not be a contributing factor in lactate production.

It could be argued that delay in determining SF lactate could bias the results. To avoid this diffulty determinations were made within two hours of obtaining the SF samples. However, it should be noted that chemical methods of stopping the reaction after obtaining SF samples have been shown to be useful. ${ }^{14}$ 
The results of the present study suggest that a low level of SF lactate points to the exclusion rather than a high value to the diagnosis of septic arthritis: indeed there is a wide scatter of SF lactic acid values in septic arthritis, seropositive RA, and crystalinduced arthritides with considerable overlap. However, it should be mentioned that values recorded in seronegative RA and SNS are much more closely grouped together (only one was above $9.4 \mathrm{mmol} / \mathrm{l}$ ), with an average value significantly lower than in seropositive RA or septic arthritis. It is suggested that synovial lactate measurement could be reliable indicator for differentiating inflammatory arthritides.

A longitudinal follow-up study of cases of monoarticular arthritis of unknown aetiology should be undertaken to determine the predictive value of synovial fluid lactate estimations.

The authors thank Dr C. G. Barnes from the Department of Rheumatology, The London Hospital, for criticism and helpful advices.

\section{References}

1 Norton W L. Ziff M. Light and electron microscopic observations of the rheumatoid synovial membrane. Arthritis Rheum 1966; 9: 589-610.

2 McCarty D J. Selected aspects of synovial membrane physiology. Arthritis Rheum 1974: 17: 289-96.

3 Espinoza R L. Vasey F B, Espinoza C G. Bocanegra C S, Germain B F. Vascular changes in psoriatic synovium. Arthritis Rheum 1982; 25: 677-83.

4 Norton W L, Lewis D, Ziff M. Light and electron microscopic observations on the synovitis of Reiter's disease. Arthritis Rheum 1966; 9: 747-57.

5 Jayson M I V. Dixon St J. Intra-articular pressure in rheumatoid arthritis of the knee. Ann Rheum Dis 1970: 29: 261-5.

6 Richman A I. Su E Y. Ho G. Reciprocal relationship of synovial fluid volume and oxygen tension. Arthritis Rheum 1981: 24: 701-5.

7 Falchuk K H, Goetzl E J, Kulka J P. Respiratory gases of synovial fluids. An approach to synovial tissue circulatory metabolic imbalance in rheumatoid arthritis. Am J Med 1970; 49: $223-31$.

8 Myers A R. Miller L M. Pinal R S. Pyoarthritis complicating rheumatoid arthritis. Lancet 1969: ii: 714-6.

9 Brook J, Reza M J. Bricknell K S, Bluestone R. Rinegold S M. Synovial fluid lactic acid. A diagnostic aid in septic arthritis. Arthritis Rheum 1978; 21: 774-9.

10 Brook J. Controni G. Rapid diagnosis of septic arthritis by quantitative analysis of joint fluid lactic acid with a monotest lactate kit. J Clin Microbiol 1978; 8: 676-9.

11 Newman R J. Curtis G D W. Slack M P E. Synovial fluid lactate levels in the diagnosis of septic arthritis. Ann Rheum Dis 1982; 41: 641 .

12 Borenstein D G, Gibbs C A. Jacobs R P. Gas-liquid chromatography analysis of synovial fluid. Succinic acid and lactic acid as markers for septic arthritis. Arthritis Rheum 1982; 8: 947-53.

13 Gobelet C. Gerster J C. Bambule J. Felber J P. Van Melle G, Saudan Y. Etude comparative des taux synoviaux de l'acide lactique, de la lacticodéshydrogénase, du glucose et de la trypsine immunoréactive. Rhumatologie 1979; 9: 325-32.

14 Arthur R E. Stern M. Galeazzi M. et al. Synovial fluid lactic acid in septic and non septic arthritis. Arthritis Rheum 1983; 26: 1499-505.

15 Curtis G D W, Newman R J, Slack M P E. Synovial fluid lactate in the diagnosis of septic arthritis. $J$ Infection 1983; 6: 239-46.

16 Kragenings J. Methodology of lactate assay. In: Bossart $\mathrm{H}$. Perret $C$, eds. Lactate in acute conditions. International symposium on lactate in acute conditions. Basle: Karger, 1978: 20-8.

17 Treuhaft P S. McCarty D J. Synovial fluid pH. lactate, oxygen and carbon dioxyde partial pressure in various joint disease. Arthritis Rheum 1971; 14: 475-84. 